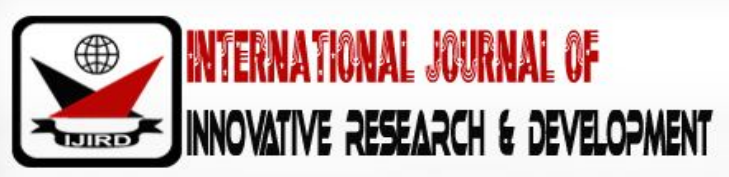

ISSN 2278 - 0211 (Online)

\section{Assessment of Road Worthiness of Long Distance Commercial Vehicles in Benin City, Edo State, Nigeria}

\begin{tabular}{c} 
Okafor Kingsley Chinedu \\
Senior Researcher, Department of Community Health, University of Benin Teaching Hospital, Nigeria \\
Azuike Emmanuel C \\
Lecturer, Department of Community Health, Chukwuemeka Odumegwu Ojukwu University, Nigeria \\
Omuemu Vivian O \\
Professor, Department of Community Health, University of Benin, Nigeria \\
\hline
\end{tabular}

Abstract:

The prevalence of road traffic accidents is on the rise, thus contributing to morbidity and mortality. Vehicular factors are responsible for $13 \%$ of road traffic crashes, $33 \%$ of vehicles are not compliant to road worthiness standards. Defects in vehicles commonly occur in the braking systems, trafficators and lights, tires and wheels, steering systems and body. Vehicle road worthiness is important in ensuring that the vehicle is safe and is road worthy. This is a current global need as highlighted in the World decade for road safety action. It is important that commercial vehicles that transport passengers are road worthy, since these vehicles claim more deaths and disability after a road accident. This emphasizes the importance of routine vehicular checks in road safety. Also, the ever increasing in number of parks, transport operators, vehicles and passengers on the road has more than ever underscored the need for fitness to drive assessment and roadworthiness checks. This study aimed at road worthiness of long distance commercial vehicles in Benin City, Edo State. A descriptive crosssectional study design was used, and data was collected from 315 commercial long-distance drivers and their vehicles. Study was done from January to October, 2013. Respondents were recruited using systematic random sampling technique. Study instruments included structured interviewer administered questionnaires (including an observational checklist). Data was analyzed using SPSS version 20. Of the 315 respondents, 273 (86.6\%) had vehicles that were aged 1-4 years while $42(13.4 \%)$ were aged 5-8 years. Over three quarters 245 (77.8\%) of vehicles had a valid MOT road worthiness certificate in place. Two hundred and eighty-five (90.5\%) vehicles of respondents were roadworthy, while $30(9.5 \%)$ were not road worthy. The statistically significant predictors of roadworthiness were vehicle age (years), having a valid Ministry of Health (MOT) roadworthiness certification in place and fitness of the driver. Only a tenth of the vehicles were road worthy. Thus, there is need to conduct annual vehicular checks and maintenance, including search for vehicular defects before departure. Enforce fitness to drive assessment especially before issuance of driver's license and the Ministry of Transport (MOT) roadworthiness certificate should be issued only to vehicles that are road worthy and defect free.

Keywords: Roadworthiness, vehicle, predictors

\section{Introduction}

Road worthiness is an important variable in road safety globally. ${ }^{1,2}$ In Nigeria, the Highway Code 27 stipulates standards for vehicle road worthiness. ${ }^{3}$ It recommends 6 monthly routine inspections for commercial vehicles and annually for vehicles older than 4 years from date of manufacture. The tests should focus on serviceability of vehicle; chassis, engine, electrical parts, transmission, brake system and safety devices. After inspection, a vehicle road worthiness certificate is issued while a validity tag is pasted on the vehicle screen for easy identification. This test is done by the vehicle inspection office (VIO). It may be a visual test, computer test or a road test. ${ }^{3}$

In one sense, a vehicle is roadworthy if it would pass a legal inspection in the jurisdiction in which it is operated. By this definition, the same vehicle could be roadworthy in one jurisdiction and not in another. Roadworthiness is not a constant attribute of the vehicle; a vehicle might be roadworthy today but not tomorrow if there is a failure of a component or components. For example, a signal lamp ceased to function. Defects may include some problems that are difficult to assess, such as a windscreen that distorts light.1,2 One method of determining the effect of roadworthiness on crash incidence is to examine the effect of periodic motor vehicle inspection (PMVI) programs on accident rates. The aim of PMVI is to eliminate 
defects from the vehicle fleet by inspecting all vehicles on a regular basis and ensuring that any detected defects are repaired before allowing the car to drive on public roads. ${ }^{1,2}$, and 4

A US study suggested that periodic roadworthiness tests could reduce the number of accidents caused by vehicle defects by about $50 \%$. Vehicle inspection programs may influence and reduce accident rates by increasing the understanding of the driver for the need for regular maintenance, safety issues and the condition of their own car. ${ }^{3}$

A number of vehicles on Nigerian roads have been fairly used before importation to Nigeria, as individuals can hardly afford brand new vehicles with all the in- built safety measures. These vehicles have depreciated safety mechanisms like faulty seat belts, expired and worn out tires, nonfunctional air bags, faulty braking system, warning lights and even factory faults. Simple vehicle safety checks in form of roadworthiness can be used to achieve the safer vehicles objective, especially for fairly used vehicles, that have lost their safety measures. Thus, stakeholders in commercial long-distance driving must ensure road worthiness of their fleet so that passengers are conveyed on vehicles that are safe and free of defects.3,4

In 2010, over 5330 Road traffic crashes (RTC) 4 occurred killing over 4065 persons and involving 8677 vehicles. There is a current re-emergence of small passenger buses (SPBS) or mini buses for commercial transport in place of large passenger buses (LPBS). This has resulted in increase in RTC in Nigeria. These SPBS are responsible for 34\% of RTA in Nigeria, 31\% are due to wagons/ cars, while trucks are responsible for $12 \%$ of RTA. 4

The prevalence of road traffic accidents is on the rise, thus contributing to morbidity and mortality. In the year 2000, road traffic injuries were the $11^{\text {th }}$ leading cause of death globally, currently, it is the $9^{\text {th }}$ leading cause of death. If nothing is done to stem this tide, by 2030, it will be the $5^{\text {th }}$ leading cause of death.5-7 Drivers carelessness is responsible for $63 \%$ of road traffic injuries ${ }^{8,9}$ while drivers wrong decision, over speeding and drunkenness caused $21 \%, 14 \%, 2.6 \%$ of road traffic injuries respectively.

Vehicle road worthiness is important in ensuring that the vehicle is safe and is road worthy. This is a current global need as highlighted in the World decade for road safety action..$^{10}$ It is important that commercial vehicles that transport passengers are road worthy, since these vehicles claim more deaths and disability after a road accident.4,6 This emphasizes the importance of routine vehicular checks in road safety. Also, the ever increasing in number of parks, transport operators, vehicles and passengers on the road has more than ever underscored the need for fitness to drive assessment and roadworthiness checks. 4,11

Vehicular factors are responsible for $13 \%$ of road traffic crashes, ${ }^{12} 33 \%$ of vehicles are not compliant to road worthiness standards. ${ }^{13}$ Defects in vehicles commonly occur in the braking systems, trafficators and lights, tires and wheels, steering systems and body.

The objectives of this study were to assess road worthiness of long distance commercial vehicles and factors affecting it.

\section{Methodology}

A descriptive cross-sectional study was carried out between Januaryto October, 2013 among 315 selected commercial long-distance drivers in Benin City.

A systematic random sampling technique was used in selecting the respondents for this study.

Data collection tools were pre-tested among selected commercial long-distance drivers operating in Auchi, Estako West Local Government Area of Edo State. The location is about 200km from Benin City. Collected quantitative data was entered and analyzed using Statistical Package for Scientific Solution (SPSS) version 20. Descriptive and inferential analysis was carried out in line with the objectives of the study. Quantitative variables that are normal in distribution such as age and weight were expressed as means \pm standard deviation. Qualitative data like gender, educational status, and marital status were presented as diagrams and percentages. Logistic regression was used to identify predictive variables for good knowledge, good practice of fitness to drive. Statistical test of association, were carried out using a 95 percent confidence interval.

Ethical approval was obtained from the ethical committee of the University of Benin Teaching Hospital. Permission was obtained from the community leader and youth leaders, while parents gave assent for questionnaires to be administered. Individual informed consent was attached to each questionnaire and the respondent gave his or her consent before the questionnaires were filled.

The assessment of roadworthiness was based on the spot examination, and subjective judgment of the researcher, thus there was no room for repeated or further examination for confirmation. There could have been inter-observer error.

\section{Results}

More than a third of the respondents 114 (36.2\%) were within the age group of 31-40 years. Ninety-one (28.9\%) were in the 41-50 years age group while 18 (5.7\%) fell within the 61-70 years age group. Most of the respondents 272 (86.3\%) were married, $28(8.9 \%)$ were single, $10(3.2 \%)$ were cohabiting, while $2(0.6 \%)$ were separated. Most of the married respondents $247(90.8 \%)$ were in monogamous marriages and $242(76.8 \%)$ had nuclear families. Almost all the respondents $311(98.7 \%)$ were males while $4(1.3 \%)$ were surprisingly females. More than half of the respondents $172(54.6 \%)$ had a secondary level of education, $112(35.6 \%)$ had a primary level of education while $12(3.8 \%)$ had no formal education. One hundred and sixty-nine (53.3\%) respondents were Benin, 48 (15.1\%) were Esan, 21 (6.6\%) were Igbo, 19 (6.0\%) were Urhobo while smaller proportions were Etsako 15 (4.8\%), Yoruba 9 (2.9\%), Isoko 8 (2.5\%), Owan 7 (2.2\%) and Itsekiri 7 
(2.2\%), Ukwuani $7(2.2 \%)$ and Ibibio $3(1.0 \%)$. Most of the respondents 300 (95.2\%) were Christians, 10 (3.2\%) were traditional in their beliefs while $5(1.6 \%)$ were Muslims. Two hundred and ninety-three $(92.7 \%)$ of the respondents were resident in Edo state, 7 (2.3\%) were resident in Lagos, 7 (2.3\%) in Delta, while smaller proportions were resident in Oyo, Kwara and Rivers [ (0.6\%) each]. (Table 1)

\section{Vehicle Road Worthiness}

Most of the respondents 273 (86.6\%) had vehicles that were aged 1-4 years while 42 (13.4\%) were aged 5-8 years. Over three quarters 245 (77.8\%) of vehicles had a valid MOT road worthiness certificate in place. (Table 2)

Eleven (3.5\%) of the respondents had brakes that needed repair, 27 (8.6\%) had steering that needed repair, $10(3.2 \%)$ had need to fix up the vehicles' body, 7 (2.2\%) had to repair the exhaust, $13(4.1 \%)$ had to repair the trafficator, $15(4.8 \%)$ had to repair the reverse lights of their vehicles, $14(4.4 \%)$ had to repair their brake lights, $13(4.1 \%)$ had to repair/ replace the radiator, 27 (8.6\%) had to replace the seatbelts. others are $1(0.3 \%)$ wheel and tires need to be replaced. (Table 3$)$

Two hundred and eighty-five (90.5\%) vehicles of respondents were roadworthy, while $30(9.5 \%)$ were not road worthy. (Table 4)

\section{Factors Influencing Vehicle Road Worthiness}

More respondents' vehicles aged older than 4years (33.3\%) were not roadworthy than those 4 years or less 16 (5.8\%). Road worthiness increased as age of the vehicle increased, this finding was statistically significant $(\mathrm{p}=0.001)$. Most of the respondents' vehicles 228 (93.1\%) with valid MOTs were roadworthy while 13 (18.6\%) of those without valid MOTs were not roadworthy. There was an increased tendency for the respondents' vehicles to be roadworthy with the presence of a valid MOT in place, this finding was statistically significant $(p=0.009)$. More drivers who were fit to drive $95(94.1 \%)$ had vehicles that were road worthy than those who were not fit to drive $180(84.0 \%)$. (Table 5)

The predictors in the model were responsible for $54.2 \%$ to $66.4 \%$ of the variation observed in the outcome variable (roadworthiness of driver's vehicles). The statistically significant predictors of roadworthiness were vehicle age (years), having a valid Ministry of Health (MOT) roadworthiness certification in place and fitness of the driver. Vehicles of age four years or less were more likely ( $\mathrm{B}=2.054$ ) be road worthy compared to those vehicles that were more than four years by odds of 7.802. This was statistically significant $(p=0.001)$. The vehicles that had MOT certification in place $(B=1.027)$ were more likely to road worthy compared to those without MOT certification with an odd of 1.358. This was statistically significant ( $\mathrm{p}=$ 0.021). Drivers who were fit to drive $(B=-1.070)$ were more likely to have vehicles that are road worthy compared to those drivers who were unfit to drive with an odd of 2.914. This was statistically significant $(p=0.015)$. (Table 6)

\begin{tabular}{|c|c|c|}
\hline Variable & Frequency $(n=315)$ & Percent \\
\hline \multicolumn{3}{|c|}{ Age (Years) } \\
\hline $21-30$ & 26 & 8.3 \\
\hline $31-40$ & 114 & 36.2 \\
\hline $41-50$ & 91 & 28.9 \\
\hline $51-60$ & 66 & 20.9 \\
\hline $61-70$ & 18 & 5.7 \\
\hline \multicolumn{3}{|c|}{ Marital status } \\
\hline Single & 28 & 8.9 \\
\hline Married & 272 & 86.3 \\
\hline Cohabiting & 10 & 3.2 \\
\hline Separated & 2 & 0.6 \\
\hline Divorced & 3 & 1.0 \\
\hline \multicolumn{3}{|c|}{ Marriage type $(\mathrm{n}=272)$} \\
\hline Monogamous & 247 & 90.8 \\
\hline Polygamous & 25 & 9.2 \\
\hline \multicolumn{3}{|c|}{ Family type } \\
\hline Nuclear & 242 & 76.8 \\
\hline Extended & 73 & 23.2 \\
\hline \multicolumn{3}{|c|}{ Sex } \\
\hline Male & 311 & 98.7 \\
\hline Female & 4 & 1.3 \\
\hline \multicolumn{3}{|c|}{ Level of education } \\
\hline No formal education & 12 & 3.8 \\
\hline Primary & 112 & 35.6 \\
\hline
\end{tabular}




\begin{tabular}{|c|c|c|}
\hline Variable & Frequency $(n=315)$ & Percent \\
\hline \multicolumn{3}{|c|}{ Level of education } \\
\hline Secondary & 172 & 54.6 \\
\hline Tertiary & 19 & 6.0 \\
\hline \multicolumn{3}{|c|}{ Ethnic group } \\
\hline Benin & 169 & 53.7 \\
\hline Esan & 48 & 15.2 \\
\hline Igbo & 21 & 6.7 \\
\hline Urhobo & 19 & 6.0 \\
\hline Etsako & 15 & 4.8 \\
\hline Yoruba & 9 & 2.9 \\
\hline Isoko & 8 & 2.5 \\
\hline Owan & 7 & 2.2 \\
\hline Itsekiri & 7 & 2.2 \\
\hline Ukwuani & 7 & 2.2 \\
\hline Ibibio & 3 & $\frac{2.4}{1.0}$ \\
\hline Othersa & 2 & 0.6 \\
\hline \multicolumn{3}{|c|}{ Religion } \\
\hline Christianity & 300 & 95.2 \\
\hline African traditional religion & 10 & 3.2 \\
\hline Islam & 5 & 1.6 \\
\hline \multicolumn{3}{|c|}{ State of residence } \\
\hline Edo & 293 & 93.0 \\
\hline Lagos & 7 & 2.3 \\
\hline Delta & 7 & 2.3 \\
\hline Oyo & 2 & 0.6 \\
\hline Kwara & 2 & 0.6 \\
\hline Rivers & 2 & 0.6 \\
\hline Others $^{b}$ & 2 & 0.6 \\
\hline \multicolumn{3}{|c|}{ Duration of driving (years) } \\
\hline $0-10$ & 84 & 26.7 \\
\hline $11-20$ & 113 & 35.9 \\
\hline $21-30$ & 63 & 20.0 \\
\hline $31-40$ & 49 & 15.6 \\
\hline $41-50$ & 6 & 1.8 \\
\hline
\end{tabular}

Table 1: Socio-Demographic Characteristics of the Respondents

\begin{tabular}{|c|c|c|}
\hline Variable & Frequency (n =315) & Percent \\
\hline \multicolumn{3}{|c|}{ Vehicle age (years) } \\
\hline $1-4$ & 273 & 86.6 \\
\hline $5-8$ & 42 & 13.4 \\
\hline Mes & 245 & 77.8 \\
\hline No & 70 & 22.2 \\
\hline
\end{tabular}

Table 2: Respondents' Vehicle Age and MOT Certification 


\begin{tabular}{|c|c|c|c|}
\hline Part Of Vehicle & $\begin{array}{c}\text { Need Replacement/ Repair } \\
\mathbf{N}(\mathbf{\%})\end{array}$ & $\begin{array}{c}\text { Needed Servicing } \\
\mathbf{N ~ ( \% ) ~}\end{array}$ & $\begin{array}{c}\text { Passed } \\
\mathbf{N}(\mathbf{\%})\end{array}$ \\
\hline Brakes & $11(3.5)$ & $21(6.7)$ & $283(89.8)$ \\
\hline Foot pedals & $1(0.3)$ & $28(8.9)$ & $286(90.8)$ \\
\hline Wheels and tires & $1(0.3)$ & $27(8.6)$ & $287(91.1)$ \\
\hline Steering & $27(8.6)$ & $0(0.0)$ & $288(91.4)$ \\
\hline Body/ cab & $10(3.2)$ & $43(13.7)$ & $262(83.2)$ \\
\hline Exhaust & $7(2.2)$ & $31(9.8)$ & $277(87.9)$ \\
\hline Mirrors & $8(2.5)$ & $32(10.2)$ & $275(87.3)$ \\
\hline Upholstery & $8(2.5)$ & $25(7.9)$ & $282(89.5)$ \\
\hline Head lamps & $2(0.6)$ & $31(9.8)$ & $282(89.5)$ \\
\hline Trafficator & $13(4.1)$ & $22(7.0)$ & $280(88.9)$ \\
\hline Horn & $7(2.2)$ & $26(8.3)$ & $282(89.5)$ \\
\hline Reverse lights & $15(4.8)$ & $23(7.3)$ & $277(87.9)$ \\
\hline Brake lights & $14(4.4)$ & $22(7.0)$ & $279(88.6)$ \\
\hline Wipers/ washers & $0(0.0)$ & $28(8.9)$ & $287(91.1)$ \\
\hline Engine sound & $0(0.0)$ & $52(16.5)$ & $263(83.5)$ \\
\hline Fan belt & $3(1.0)$ & $42(13.3)$ & $270(85.7)$ \\
\hline Radiator & $13(4.1)$ & $28(8.9)$ & $274(87.0)$ \\
\hline Seat and seatbelts & $27(8.6)$ & $23(7.3)$ & $265(84.1)$ \\
\hline Registration plates & $0(0.0)$ & $32(10.2)$ & $283(89.8)$ \\
\hline Wind screen & $0(0.0)$ & $31(9.8)$ & $284(90.2)$ \\
\hline
\end{tabular}

Table 3: Observational Checklist of the Respondents' Vehicles (2)

\begin{tabular}{|c|c|c|}
\hline Vehicle Status & Frequency (n =315) & Percent \\
\hline Roadworthy & 285 & 90.5 \\
\hline Not roadworthy & 30 & 9.5 \\
\hline Total & 315 & 100.0 \\
\hline
\end{tabular}

Table 4: Respondents' Vehicle Status (Roadworthiness)

\begin{tabular}{|c|c|c|c|c|c|c|}
\hline \multirow[t]{2}{*}{ Variable } & & \multicolumn{4}{|c|}{ Vehicle Roadw orthiness } & \multirow[b]{2}{*}{ P Value } \\
\hline & & $\begin{array}{c}\text { Roadworthy } \\
\text { N(\%) }\end{array}$ & $\begin{array}{c}\text { Not Roadworthy } \\
\text { N(\%) }\end{array}$ & $\begin{array}{l}\text { TOTAL } \\
\text { N(\%) }\end{array}$ & $\mathrm{X}^{2}$ & \\
\hline \multirow[t]{2}{*}{ Vehicle age } & $\leq 4$ years & $257(94.1)$ & $16(5.8)$ & $273(100.0)$ & \multirow{2}{*}{56.207} & \multirow[t]{2}{*}{$0.001 *$} \\
\hline & $>4$ years & $28(66.7)$ & $14(33.3)$ & $42(100.0)$ & & \\
\hline \multirow[t]{2}{*}{ Valid MOT in place } & Yes & $228(93.1)$ & $17(6.9)$ & $245(100.0)$ & \multirow[t]{2}{*}{8.550} & \multirow[t]{2}{*}{ 0.009* } \\
\hline & No & $57(81.4)$ & $13(18.6)$ & $70(100.0)$ & & \\
\hline \multirow[t]{2}{*}{ Fitness to drive } & Fit & $95(94.1)$ & $5(4.9)$ & $1019100.0)$ & 5.099 & $0.037 *$ \\
\hline & Unfit & $180(84.0)$ & $25(15.9)$ & $214(100.0)$ & & \\
\hline
\end{tabular}

Table 5: Factors Influencing Vehicle Roadworthiness Significant*

\begin{tabular}{|c|c|c|c|c|c|}
\hline \multicolumn{2}{|c|}{ Predictors } & B (Regression Coefficient) & \multirow{2}{*}{ P-Value } & \multirow{2}{*}{ Odd Ratio } & \multicolumn{2}{c|}{ 95\% C.I. For Odd Ratio } \\
\cline { 4 - 6 } & & & & Lower & Upper \\
\hline Vehicle Age (years) & & & & & \\
\hline$\leq 4$ years** & 2.054 & $.001^{*}$ & 7.802 & .053 & 0.312 \\
\hline >4 years & & & 1 & & \\
\hline MOT in place & & & & & 6.688 \\
\hline No & 1.027 & $.021^{*}$ & 1.358 & 1.166 & \\
\hline Yes** & & & 1 & & 6.902 \\
\hline FTD status & -1.070 & $.015^{*}$ & 2.914 & 1.231 & \\
\hline Unfit & & & 1 & & \\
\hline Fit** & -2.627 & .271 & -.072 & & \\
\hline Constant & -6.2712 & & & \\
\hline
\end{tabular}

Table 6: Determinants of Vehicle Road Worthiness

**Reference Category, R2 =54.2\% - 66.4\%, Significant*, C.I = Confidence Interval 


\section{Discussion}

Most of the vehicles were within the ages 1-4 years, thus requiring annual routine inspections for road worthiness. ${ }^{1}$ Most the respondents' vehicles age 4 years and older were not roadworthy while most of the vehicles less than 4 years were roadworthy, this finding was statistically significant. Vehicles are known to decrease in roadworthiness over time. Using standard visual checks on relevant vehicle parts, it revealed that 3.5\% of the vehicles had brakes that needed repair, $8.6 \%$ had steering that needed repair, 3.2\% needed to fix up the vehicles' body, $2.2 \%$ needed to repair the exhaust, $4.1 \%$ needed to repair the trafficator, $4.8 \%$ needed to repair the reverse lights of their vehicles, $4.4 \%$ needed to repair their brake lights, $4.1 \%$ had to repair/ replace the radiator, $8.6 \%$ had to replace the seatbelts and $0.3 \%$ needed wheel and tires replacement. Findings documented by the Institute for Research in Public Safety (IRPS) in Monroe County Indiana in United States, ${ }^{12,14}$ revealed slightly higher proportions. Accounting for this may be the fact that vehicles were investigated by automotive engineers, combining detailed physical evidence and interview at the accident scene after the crash.

Most (90.5\%) of the respondents' vehicles were roadworthy, while $9.5 \%$ were not road worthy and should not be on the road. Most of the respondents' vehicles (93.1\%) with valid MOTs were roadworthy while (18.6\%) of those without valid MOTs were not roadworthy. There was an increased tendency for the respondents' vehicles to be roadworthy with the presence of a valid MOT in place, this finding was statistically significant. This validates the certification of road worthiness by the Driving and transport agencies. In similar studies done in Northern Ireland, ${ }^{13}$ by the Drivers and Vehicle Testing Agency, $67 \%$ of the vehicles were roadworthy, while $33 \%$ were not road worthy. This difference may be due to the unavailability of computerized testing equipment may have increased the number of defects detected. These defects can lead to road crashes as seen in several studies done. $2,12,14,15$

\section{Conclusion and Recommendation}

A tenth of vehicles used by commercial long-distance drivers were not road worthy. The age of the vehicle, MOT and FTD status of the driver were statistically significant factors. The following recommendations are advanced based on the findings from this study.

Commercial drivers, drivers' union and owners of transport companies should conduct monthly vehicular checks and maintenance, including search for vehicular defects before departure.

Road Safety Officers and Drivers and Vehicle Licensing Authority should enforcement regular vehicular assessment before issuance of road worthiness certificate. The Ministry of Transport (MOT) roadworthiness certificate should be issued only to vehicles that are road worthy and defect free.

\section{References}

i. Rechnitzer G, Haworth N, Kowadlo N. The effect of vehicle road worthiness on crash. Victoria, Monash University Accident Research Center, Australia; 2000:23- 56.

ii. Rompe K. \& Seul E. Advantages and disadvantages of conducting roadworthiness tests to monitor the mechanical condition for private cars, the impact of such tests on road safety, environmental protection and the renewal of the vehicle fleet and the scope for introducing road. New York. USA. 1985: 2 - 5.

iii. Federal Road Safety Commission. Federal road safety annual report. Abuja, Nigeria. 2006:22- 67.

iv. Federal Road Safety Commission. Federal road safety annual report. Abuja, Nigeria. 2008:3-5

V. Peden M, Scurfield R, Sleet D. United Nations road safety collaboration: a handbook of partner profiles. Geneva, Switzerland. 2005:12-23.

vi. World Health Organization. Second Global Status report. Geneva, Switzerland; 2011:2-3. Available at: http:/ / www.who.int/ violence_injury_prevention/road_safety_status/ 2009/ en/index.htm. Accessed 11:09: 2012.

vii. Adofo M G. Poor vision, refractive errors and barriers to treatment among commercial vehicle drivers in the Cape Coast municipality. African Health Sciences. 2011; 11(1):97-102.

viii. Jacobs G, Aeron-Thomas A. Estimating global road fatalities. Crow- thorne Transport Research Laboratory; 2000:3435.

ix. Foundation for Automobile safety. FIA foundation annual review. 2011: 20- 45. Available at www.fiafoundation.org. Accessed 11:09: 2012.

X. Twagirayezu E, Teteli R, Bonane A, Rugwizangoga E. Road traffic injuries at Kigali University Central Teaching Hospital, Rwanda. East and Central African Journal of Surgery. 2008; 13(1): 1-4.

xi. Watkins K. The Missing Link: Road traffic injuries and the Millennium Development Goals. UNESCO, 2010:23-30. Available at.www.makeroadssafe.org.Accessed 11:09: 2012

xii. Treat JR. Tri-level study of the causes of traffic accidents: an overview of final results; USA. In: American Association for Automotive Medicine Conference; 1977:402.

xiii. Driver \& Vehicle Testing Agency. Vehicle roadworthiness survey report. Northern Ireland. 2004:23- 34.Available at www.dvtani.gov.uk. Accessed 11:08: 2012. 
xiv. Haw orth N, Vulcan P, Bowland L \& Bowland PN, Case-control study of fatal single- vehicle crashes. Reports No. 120 \& 122. Melbourne; 1997:4-7.

XV. Grandel J. Investigation of the technical defects causing motor vehicle accidents. Field Accidents: Data collection, analysis, methodologies, and crash injury reconstructions. Detroit; United states 1985: p 23-35. 